\title{
Effect of Salinity Stress on Various Growth and Physiological Attributes of Two Contrasting Maize Genotypes
}

\author{
Noreen Zahra ${ }^{1}$ \\ https://orcid.org/0000-0003-4599-0901 \\ Zulfiqar Ali Raza ${ }^{*}$ \\ https://orcid.org/0000-0003-2892-6481
}

\section{Saqib Mahmood ${ }^{1}$}

${ }^{1}$ Government College University, Department of Botany, Faisalabad-Pakistan; ${ }^{2}$ National Textile University, Chemistry Research Laboratory, Pakistan.

Received: 2020.02.11; Accepted: 2020.11.18.

*Correspondence: zarazapkl@yahoo.com; Tel.: +92-41-9230081 (ZA Raza)

\section{HIGHLIGHTS}

- This study dealt with cultivation of two local maize genotypes under sanity stress.

- Various growth and morphological parameters of the plants were under taken.

- Phenylalanine could successfully increase the salinity tolerance at seedling stage.

Abstract: The response of two local maize (Zea mays L.) genotypes designated as Sahwal-2002 (salttolerant) and Sadaf (salt-sensitive) to salt stress was investigated under controlled growth conditions. The role of phenylalanine and seed priming under salt stress in maize with different morphological parameters were studied. The genotype Sadaf, being salt-tolerant, experienced more oxidative damage than the Sahiwall-2002 genotype under salt stress. The salinity affected both growth and physiological attributes of the maize species whereas the phenylalanine successfully increased the salinity tolerance in maize species at the seedling stage.

Keywords: genotype; growth attributes; maize; salinity stress.

\section{INTRODUCTION}

Throughout their life cycle, all plants are subjected to a massive amount of stresses. The plants respond to these stresses in different ways depending upon their type and the sources of stresses. Drought and salinity are two major environmental factors that reduce plant productivity [1]. Many factors interrelate and alter the effect of salinity such as soil fertility, humidity, ambient temperature, light, irrigation, and so on [2]. Generally, the survival and growth of plants are measured to determine the tolerance of plants to salinity [3].

Salts, for instance, sodium ion $\left(\mathrm{Na}^{+}\right)$based, can cause severe ionic toxicity; the reason is that the $\mathrm{Na}^{+}$ ions are not easily sequestered into the vacuoles of cells. The striking effects of high salt concentration on plants reduce the uptake of water. Consequently, the water osmotic gradient is disturbed between soils and plants. On increasing the salt concentration in soil, the water decreases the osmotic potentials as the plant can't uptake the water. Stress and high salinity would lead to physiological drought conditions and ionic 
toxicity which affect plant growth and development [4]. Consequently, high salinity affects mostly all aspects of plant physiology and metabolism. Meanwhile, some hyper-ionic and hyperosmotic stresses are produced due to salinity which leads to plant demise. The high salinity can also injure the plant cells which leads to growth inhibition. The effect of salinity causes some toxic effects inside the plant. The salts can accumulate in the mature leaves hence dying them. The leaves are a lifeline for the plants [5]. The high concentration of salinity affects the helical growth and cortical microtubule in Arabidopsis [6], thus water-deficit stress for plants is happened [7]. The interactions of salts may result in nutrient imbalances and deficiencies. The salt causes the wilting of the leaves even when the much moisture (or water content) is present and the leaves become dull and having gray leaf tips. The salinity causes also adverse effects in the form of physiological dysfunctions and a decrease in the yield of a crop [8,9].

Maize (Zea mays L.), after wheat and rice, is ranked the third most significant cereal crop in Pakistan and is known as "King of grain crops". Humans consume 8 to $10 \%$ of the crop in the form of by-products including glucose, starch and corn oil, etc. It is also a source of feed, food, and fodder. After fermentation, maize starch is also used as biofuel (as ethanol) world widely. The phenomenon of priming is used for many decades. "Priming" (i.e., pre-germination treatments) is the treatment of plants with a variety of natural and synthetic compounds. The primed plants have the ability of faster and stronger growth. The primed seeds have strong cellular defense responses against pathogens, insects, and biotic stresses [10].

The priming treatments prevent the emergence of radical but enhance the germination and initiate germination-related processes [11]. The priming gives direct benefits and works for more uniform stands, faster emergence, and stronger plants. It is also better for drought tolerance. In many crops, it provides earlier flowering and higher grain yield [12,13]. Crops often fail to establish quickly and uniformly in the semi-arid tropics area, so plant populations decrease. In several crops, establishment, stand, and yield could be increased by seed priming. Good establishment increases tolerance to dry spells, competitiveness against weeds, and yields [14]. The priming avoids the time and costs consuming need for again sowing [15]. Seed priming induces endosperm weakness by hydrolase activities [16].

In the vision of increasing adversaries due to salinity stress, there is a great need to find out the stresstolerant verities, indicators, and mechanism of salt stress which can be used to increase the maize productivity in those areas of the world which are under salt stress. The role of phenylalanine and seed priming in maize and different morphological parameters were studied under salt stress.

\section{MATERIAL AND METHODS}

\section{Materials}

Sodium chloride was purchased from Merck and phenylalanine from Sigma-Aldrich. All chemicals were of analytical grade and used without any pretreatment. The sand was sampled from local agricultural land. All irrigations were done with distilled water.

\section{Maize species}

Synthetic maize genotype seeds, kindly donated by Ayub Agricultural Research Institute, Faisalabad and Millet Research Institute, Sahiwal-Pakistan, were designated as Sadaf and Sahiwal-2002, respectively.

\section{Growth conditions}

All seed verities were sown in separate plastic pots (of height $10 \mathrm{~cm}$, and circumference of $82 \mathrm{~cm}$ at the top and $70 \mathrm{~cm}$ at the bottom). Each pot was filled with dried washed sand as $2.5 \mathrm{Kg}$, previously washed with tap water and then distilled water for several times. A hole was made in each pot for leaching during the replacement of the solution. Distilled water was used for marinating the best possible moisture for germination and seedling establishment. A set of 12 seeds were sown in each pot with control or with phenylalanine priming. The pots were arranged in a randomized manner and repositioned randomly at various times during the experimental study. The experiment designed with three replicates of two varieties, three priming treatments, and two salinity levels

The plants were allowed to grow for $18 \mathrm{~d}$ under salt stress conditions with full strength Hoagland's nutrient solution. The plant was then divided into root and shoots fractions. Stress tolerance was evaluated based on the percentage of germination, dry weight, and fresh weight. For dry weight, root and shoots were kept in the paper bags and kept in an oven at $60^{\circ} \mathrm{C}$ for $7 \mathrm{~d}$. Fresh plant leaves were placed in the zipper bags and were kept in the refrigerator for the determination of $\mathrm{Na}+$ and $\mathrm{Cl}$ effect on the maize. The screening proved Sadaf 
as salt-sensitive andSahiwal-2002 as salt-tolerant, hence these species were selected as cultivars.

\section{Salinity treatment}

An aliquot of $100 \mathrm{~mL}$ of $1 \mathrm{M} \mathrm{NaCl}$ solution with full strength Hoagland's nutrient salinity was put into each pot. In control experiments, only full-strength Hoagland's nutrient medium was provided.

\section{Phenylalanine priming}

The phenylalanine priming was done by using the phenylalanine concentrations of 0.0 (P0 i.e., control), $0.8(\mathrm{P} 1)$, and $1.0 \%(\mathrm{w} / \mathrm{v})(\mathrm{P} 2)$.

\section{Growth attributes}

The growth attribute consider were: germination percentage, leaf area, fresh and dried root and shoot weights, and root and shoot lengths.

\section{Physiological attributes}

The physiological attributes included the total chlorophyll, chlorophyll a (Chl-a), and chlorophyll b (Chlb) contents were determined by using the modified method of Arnon [17]. The carotenoids contents were estimated as described by the method of Davis [18].

\section{Statistical analysis}

The presence or absence of significant differences among different factors was ascertained with analysis of variance (ANOVA). Computer software COSTAT (CoHort software, 2003, Monterey, California) was used for all statistical analyses and MS-Excel was used to graphically present the data. The experiments were run in triplicate and the data reported are the average of three concordant readings.

\section{RESULTS AND DISCUSSION}

\section{Effect of salinity on plant growth}

The saline soil affects the development, growth, yield, and physiological and metabolic disturbances in plants. The plants are affected adversely to the seed germination, survival, morphological characteristics, development and yield, and its components [19]. By affecting endogenous growth hormones, salinity stress reduces the growth and yield components of soybean. The reduction in growth is a result of physiological responses including modification of water status, mineral nutrition, ion balance, stomatal behavior, and photosynthetic effectiveness [20]. Increasing salinity causes a decrease in fresh or dry weight. Seedling growth shoot height and root length were the most sensitive to salt stress [11]. Salinity stress decrease the leaf size, internode, and length leading to the stunted growth of salt marsh and sand-dune plants [21].

The salinity reduces growth via lowering the water potential in the root zone, specific ion toxicity, and nutritional imbalance rises with the elevated internal concentration of $\mathrm{Na}+$ ions [20]. In the present work, stress decreased the root fresh weight, dry weight and germination percentage although for all growth parameters; Sadaf showed more sensitivity as compared to Sahiwal-2002. Measurement of growth characters of the plant is the vital index of changes produced under stressed conditions. In this study, the measurements were made for changes in the length, fresh, dry weight, leaf area, and generation rate of two maize verities Sahiwall-2002 and Sadaf under salinity.

\section{Germination percentage}

The statistical data showed that differences between the varieties and priming were significant $(\mathrm{P}<0.05)$ for germination percentage (Table 1). But the differences between stresses were non-significant. The interactions of these factors' verities* stress, variety* priming, and stress* ${ }^{*}$ priming and variety* stress ${ }^{*}$ priming were significant. Sahiwal-2002 increased with a second level of priming under control conditions. The salinity lowered the germination percentage of Sadaf markedly whereas Sahiwal -2002 maintained its percentage even under stress (Figure 1a). Priming improved this attribute in both cultivars. The figures with alphabets on the columns indicate significant $(P<0.05)$ interactions of varieties priming and stress treatment.

During the germination under salt stress, the seeds require a higher amount of water uptake due to the 
accumulation of the soluble solutes around the seeds which cause an increase in osmotic pressure [22]. This results in extreme uptake of the ions which cause ion toxicity in the plant reduced the water potential gradient between external environments and the seed inhibits the primary root emergence [23].

\section{Leaf area}

The statistical data showed that differences between varieties and priming were non-significant for the leaf area (Table 1). But the differences between stress and control were significant. The interactions of these factors' verities*stress, verities*priming, and stress*priming were non-significant $(P>0.01)$. But the interaction of stress*priming was significant. Sadaf and Sahiwal-2002 showed non- significant effect on the leaf area under saline conditions (Figure 1b).

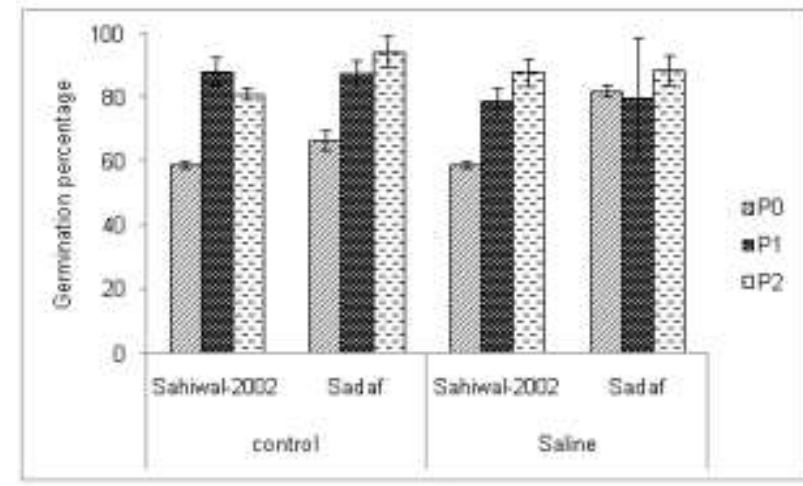

(A)

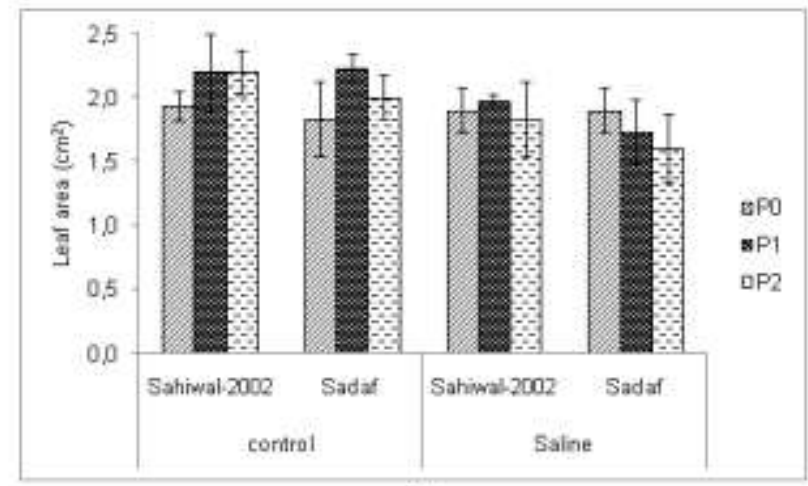

(B)

Figure 1. Priming effect changes in the (a) germination percentage and (b) leaf area of different tolerant varieties under saline and control conditions

\section{Fresh weight of root and shoot}

The result showed that priming successfully increased the shoot fresh weight of both cultivars (Figure 2a). However, this rise was greater in Sahiwal-2002 than in Sadaf. The stress significantly decreased the root fresh weight of Sadaf however; Sahiwall-2002 maintained its level even in stress. The varietal difference for this attribute was marked under stress. Priming notably improved root fresh weight in both cultivars. For the shoot, the dry weight effect of stress and priming was almost negligible. Salinity lowered the dry weight of the roots of both varieties. Priming successfully increased dry weight in both cultivars under both circumstances. Varieties difference and the effect of stress for shoot length were negligible but priming showed a positive effect upon shoot length of Sahiwal-2002 in both rooting media. However, it failed to impose any positive effect upon stressed seedlings of Sadaf. The root length was maintained in both cultivars in stress. As regards the effect of priming treatment, it increased the length of both cultivars as compared to nonprime seedlings in both environmental conditions. This rise was comparatively greater in Sahiwal-2002. The salinity lowered the germination percentage of Sadaf markedly whereas Sahiwal-2002 maintained its percentage even under stress. The priming improved this attribute in both cultivars.



(A)

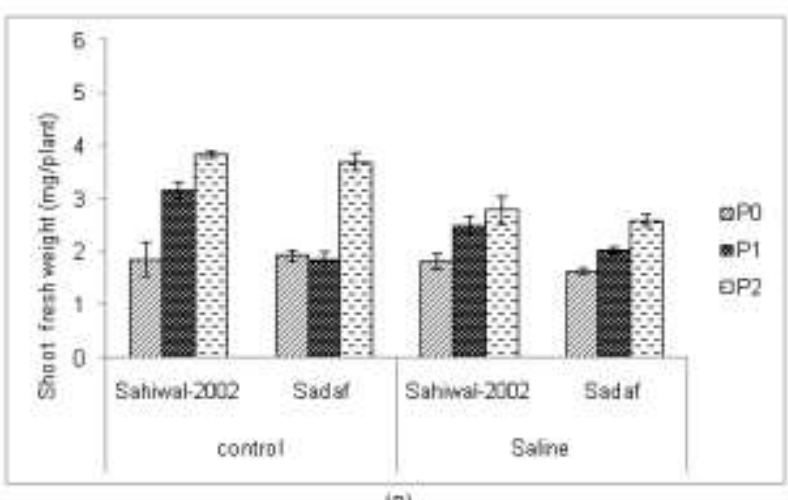

(घ)

Figure 2. Priming effect on fresh weight changes of (a) root and (b) shoot of different tolerant varieties under saline and control conditions 
Table 1. Mean squares from ANOVA) of data for germination percentage and leaf area and other growth attributes of two maize (Zea mays L.) cultivars when different levels of Priming were applied to salt-stressed or non-stressed plants at the seedling stage.

\begin{tabular}{|c|c|c|c|c|c|c|c|c|c|}
\hline \multirow{3}{*}{$\begin{array}{l}\text { Sources } \\
\text { of } \\
\text { variatio } \\
\mathrm{n} \\
\text { Variety }\end{array}$} & \multirow[t]{2}{*}{$d f$} & \multirow{2}{*}{$\begin{array}{l}\text { Germination } \\
\text { percentage }\end{array}$} & \multirow[t]{2}{*}{ Leaf area } & \multicolumn{2}{|c|}{ Fresh weight } & \multicolumn{2}{|c|}{ Dry weight } & \multicolumn{2}{|c|}{ Length } \\
\hline & & & & Root & Shoot & Root & Shoot & Root & Shoot \\
\hline & 1 & $518.82716^{* *}$ & $0.1344444 n s$ & $5.1000694^{* * *}$ & $0.050625^{\star * *}$ & $0.050625^{\star * *}$ & $0.0025 \mathrm{~ns}$ & $1369^{\star \star \star}$ & $30.433611^{* *}$ \\
\hline Stress & 1 & $0.1111111 \mathrm{~ns}$ & $0.5377778^{* *}$ & 0.0850694 ns & $0.1034694^{* * *}$ & $0.1034694^{* * *}$ & $0.09^{* *}$ & $266.77778^{* * *}$ & 580.00694 *** \\
\hline Prim & 2 & $1531.4938^{\star \star \star}$ & $0.0719444 \mathrm{~ns}$ & $8.7864583^{\star \star \star *}$ & $0.0807194^{\star \star \star}$ & $0.0807194^{* * *}$ & $0.0104861 \mathrm{~ns}$ & $361.52083^{\star \star \star}$ & $72.393611^{\star \star *}$ \\
\hline$V^{*} S$ & 1 & $5.4444444 \mathrm{~ns}$ & $0.01 \mathrm{~ns}$ & $1.3417361^{* \star *}$ & $0.015625^{\star}$ & $0.015625^{\star}$ & 0.0544444 * & $132.25^{* * *}$ & $38.233611^{* *}$ \\
\hline$V^{*} P$ & 2 & $177.12346^{*}$ & $0.0219444 n s$ & $0.4617361^{* \star *}$ & 0.0094083 ns & $0.0094083 \mathrm{~ns}$ & $0.0077083 \mathrm{~ns}$ & $112.14583^{* * *}$ & 24.605278 *** \\
\hline$S^{*} P$ & 2 & $203.81481^{*}$ & $0.1536111^{*}$ & $0.3134028^{* *}$ & $0.0380528^{* \star *}$ & $0.0380528^{* * *}$ & 0.0264583 * & $97.215278^{* \star \star}$ & 9.6052778 ** \\
\hline$V^{*} S^{*} P$ & 2 & $149.37037^{*}$ & $0.0258333 \mathrm{~ns}$ & $2.6159028^{\star \star \star}$ & $0.0084083 \mathrm{~ns}$ & $0.0084083 \mathrm{~ns}$ & $0.0159028 \mathrm{~ns}$ & $9.1458333 \mathrm{~ns}$ & $9.6052778 \mathrm{~ns}$ \\
\hline Error & 24 & $41.253086<-$ & $0.045<-$ & $0.0464583<-$ & $0.0029556<-$ & $0.0029556<-$ & $0.0076389<-$ & $4.7569444<-$ & $2.9625<-$ \\
\hline
\end{tabular}

Note: $\mathrm{ns}=$ non-significant; ${ }^{*}{ }^{* *},{ }^{* \star *}$ significant at $0.05,0.01$, and 0.001 levels, respectively. $\mathrm{V}=$ variety; $\mathrm{S}=\mathrm{stress} ; \mathrm{P}=$ priming

Table 2. Mean squares from Analyses of variance (ANOVA) of data for Chl-a, Chl-b, Car, and Total Chlorophyll content of leaves of two maize (Zea mays L.) cultivars when different levels of Priming were applied to salt-stressed or non-stressed plants at the seedling stage.

\begin{tabular}{|c|c|c|c|c|c|}
\hline Sources of variation & $d f$ & Chl-a & Chl-b & Car & Total chlorophyll \\
\hline Variety & 1 & $2.5715 \mathrm{e}-4^{*}$ & $3.2027 e-6$ * & $2.5503 e-5 n s$ & $3.825 e-6$ * \\
\hline Stress & 1 & $4.5867 e-4^{* *}$ & 7.8163e-7ns & $3.0428 \mathrm{e}-5 \mathrm{~ns}$ & $2.2114 \mathrm{e}-7 \mathrm{~ns}$ \\
\hline Prim & 2 & $0.0034447^{* * *}$ & $5.2135 \mathrm{e}-6^{* * *}$ & $0.0043901^{* \star *}$ & $2.2114 \mathrm{e}-7^{* \star *}$ \\
\hline $\mathrm{V} * \mathrm{~S}$ & 1 & $0.0052211^{* * *}$ & $2.0141 e-5^{* * *}$ & $0.0013699 * * *$ & $3.3851 e-5 * * *$ \\
\hline$V^{*} P$ & 2 & $1.716 \mathrm{e}-4^{*}$ & $1.1379 e-6 n s$ & $2.6962 \mathrm{e}-4^{* *}$ & $8.8522 \mathrm{e}-7 \mathrm{~ns}$ \\
\hline$S^{*} P$ & 2 & $5.303 e-4$ *** & $8.1041 \mathrm{e}-7 \mathrm{~ns}$ & $6.1667 e-4^{* \star}$ & $8.4772 \mathrm{e}-7 \mathrm{~ns}$ \\
\hline$V^{*} S^{\star} P$ & 2 & $0.0030024^{* * *}$ & $1.0333 e-5 * * *$ & $1.0213 e-4$ ns & $1.4624 \mathrm{e}-5^{\star \star \star}$ \\
\hline Error & 24 & $4.3232 e-5<-$ & $4.9649 \mathrm{e}-7<-$ & $4.4245 e-5<-$ & $5.4652 e-7<-$ \\
\hline
\end{tabular}

Note: $\mathrm{ns}=$ non-significant; ${ }^{*},{ }^{\star *},{ }^{* \star *}$ significant at $0.05,0.01$, and 0.001 levels, respectively. $\mathrm{V}=$ variety; $\mathrm{S}=$ stress; $\mathrm{P}=$ priming 
The statistical data for the fresh weight of root revealed significant differences in verities but nonsignificant $(P>0.01)$ differences in salt stress for fresh root weight (Table 1$)$. The priming effect, variety interaction with stress, variety interaction with priming, and stress interaction with priming was significant. Moreover, the verity interaction with stress and priming was also significant. The stress significantly decreased the root fresh weight of Sadaf; however, Sahiwal-2002 maintained its level even in stress. The varietal difference for this attribute was marked under stress. Priming notably improved root fresh weight in both cultivars.

Results regarding shoot fresh weight indicated significant differences $(a s p<0.01)$ in the varieties and salt stress treatment for fresh shoot weight (Table 1). But the interaction of variety and stress was nonsignificant. There were significant varieties* ${ }^{*}$ priming, stress ${ }^{*}$ priming, and variety ${ }^{*}$ stress ${ }^{*}$ priming interactions. The effect of salinity in nonprime seedlings was almost negligible in both varieties under both environmental conditions. The priming successfully increased the shoot fresh weight of both cultivars. However, this raise was greater in Sahiwal-2002 than Sadaf (Figure 2b).

\section{The dry weight of root and shoot}

The statistical data showed that differences between the varieties, stress, and priming were significant for dry root weight (Table 1). The interactions being verities*stress and stress*priming were also significant. But the interactions of these factors' variety ${ }^{*}$ priming and variety ${ }^{*}$ stress ${ }^{*}$ priming were non-significant $(P>0$. 05). Salinity lowered the dry weight of the roots of both varieties. Priming successfully increased dry weight in both cultivars under both circumstances (Figure 3a).

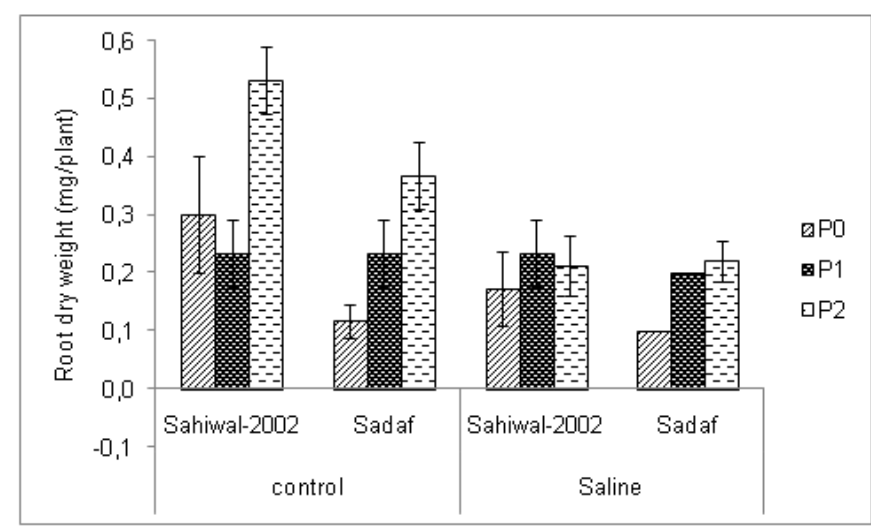

(A)

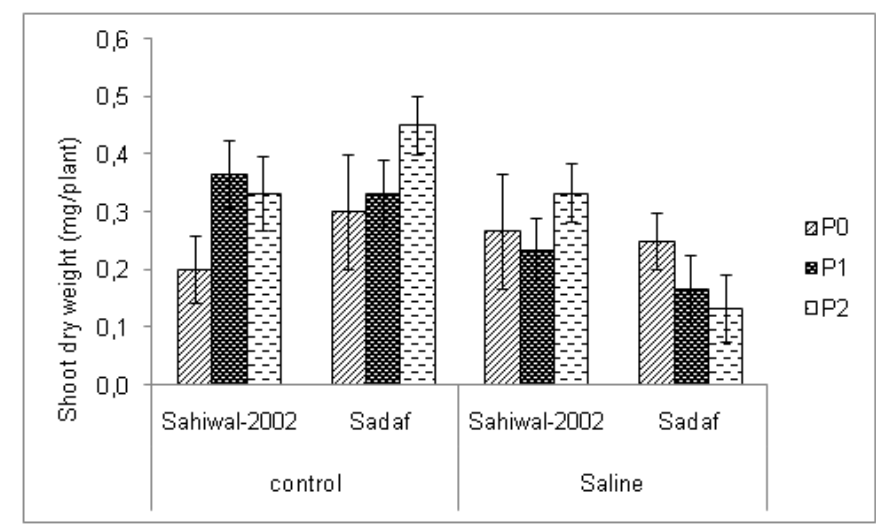

(B)

Figure 3. Priming effect on dry weight changes of (a) root and (b) shoot of different tolerant varieties under saline and control conditions

The statistical data showed that differences between the varieties and priming were non-significant; whoever the stress differences were significant for dry shoot weight (Table 1). The interactions of these factors' verities*'stress and stress* priming were also significant. But the interactions of these factors' variety ${ }^{*}$ priming and variety*stress ${ }^{*}$ priming were non-significant $(P>0.05)$. For shoot dry weight, the effect of stress and priming was almost negligible (Figure $3 b$ ).

\section{Root and shoot lengths}

The statistical data showed that differences between the varieties, priming, and stress were significant for root length (Table 1). The interactions of these factors' verities* ${ }^{*}$ stress, variety ${ }^{*}$ priming, and stress ${ }^{*}$ priming were also significant $(P<0.05)$. But the interactions of variety ${ }^{*}$ stress ${ }^{*}$ priming were non-significant $(P>0.05)$. Root length was maintained in both cultivars in stress. As regards the effect of priming treatment it increased the length of both cultivars as compared to nonprime seedlings in both environmental conditions. This rise was comparatively greater in Sahiwal-2002 (Figure 4a).

The statistical data showed that differences between the varieties, priming, and stress were significant for shoot length (Table 1). The interactions of these factors' verities**stress, variety* priming, and stress ${ }^{*}$ priming were also significant. But the interactions of variety*stress ${ }^{*}$ priming were non-significant $(P>0.05)$. Varieties difference and the effect of stress for shoot length are negligible but priming showed a positive effect upon shoot length of Sahiwal-2002 in both rooting media. However, it failed to impose any positive effect upon stressed seedlings of Sadaf (Figure 4b). 


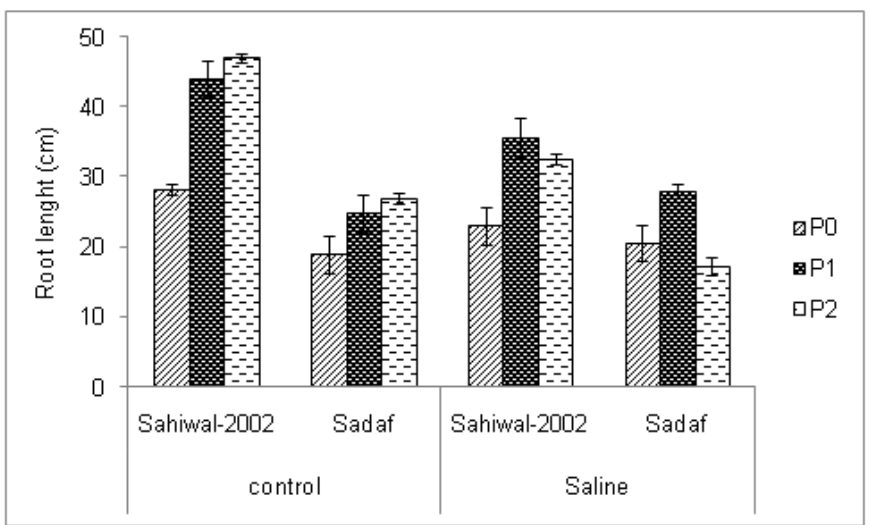

(A)

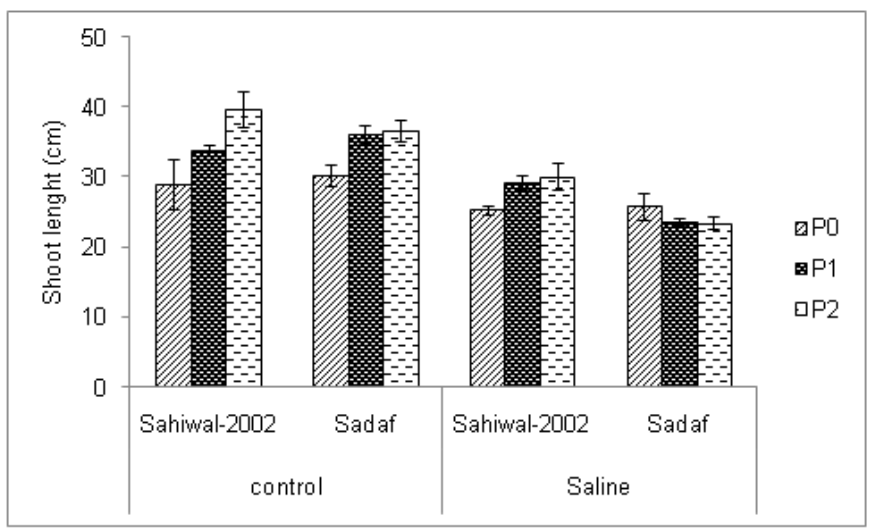

(B)

Figure 4. Priming effect on length changes of (a) root and (b) shoot of different tolerant varieties under saline and control conditions.

\section{Chlorophyll contents}

Photosynthetic activity is considered one of the major factors which control plant growth [24]. The salinity indirectly slows down photosynthesis in plants and photosynthesis is directly related to stomatal conductance, chlorophyll contents, transpiration, and water potential. Leaf photosynthesis can be lowered by the reduction of stomatal conductance as a result of water imbalance under salt stress [25]. The rate of photosynthesis in salt-tolerant species generally has been least affected than that in salt-sensitive species [9]. Whereas, in the present study, both varieties exhibited a similar level of photosynthetic attributes indicating that the difference of resistance of Sahiwal-2002 and Sadaf may not be directly related to these attributes.

The statistical data showed that differences between the priming, variety, and stress were significant for Chl-a contents (Table 2). The interactions of these factors' varieties*stress, verities* ${ }^{*}$ priming, stress ${ }^{*}$ priming, and variety*stress*priming interaction were also significant. Both varieties showed a similar level of Chl-a in both conditions when nonprime. The priming increased this attribute in stress only in Sadaf and in Sahiwal under controlled conditions (Figure 5a).

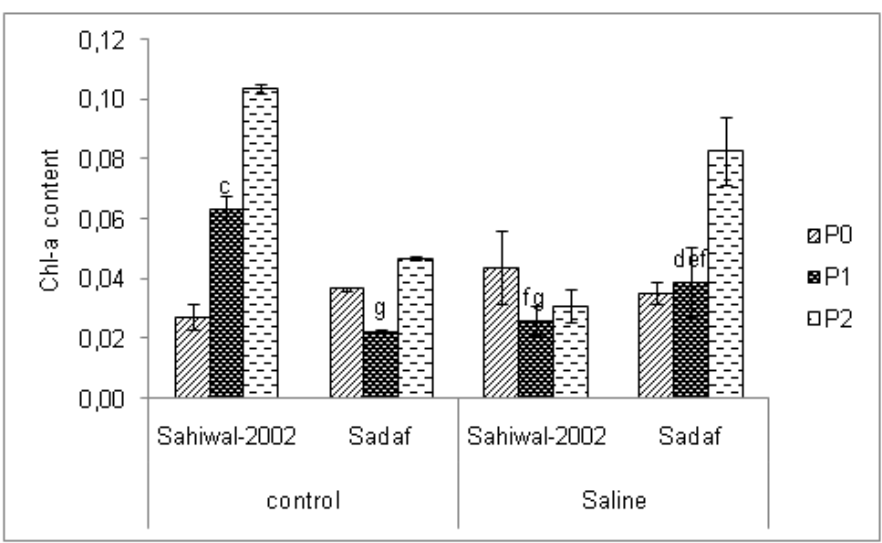

(A)

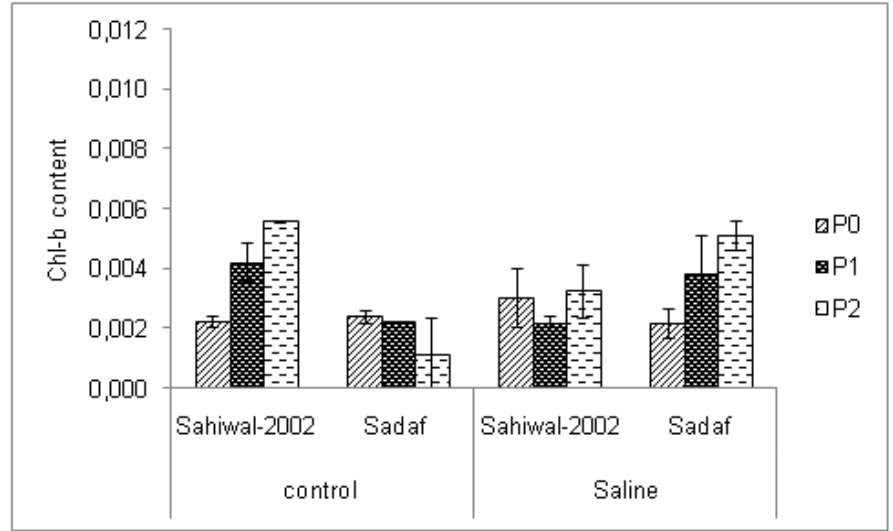

(B)

Figure 5. Priming effect changes on (a) Chl-a and (b) Chl-b contents of different tolerant varieties under saline and control conditions.

The statistical data showed that differences between the variety and priming were significant for Chl-b contents (Table 2). The differences between stresses were non-significant. The interactions between variety ${ }^{*}$ stress and variety ${ }^{*}$ stress ${ }^{*}$ priming were significant. But the interactions of the factors of variety ${ }^{*}$ priming and stress ${ }^{*}$ priming were non-significant. Likewise, Chl-a both varieties showed a similar level of Chl- $b$ in both conditions when nonprime. The priming increased this attribute in stress only in Sadaf and in Sahiwal under controlled conditions (Figure 5b).

The statistical data showed that differences between the variety and priming were significant but the differences between stresses are non-significant for the total for chlorophyll contents (Table 2). The interaction between variety ${ }^{*}$ stress and variety* ${ }^{*}$ stress ${ }^{*}$ priming was significant. But the interactions of these factor variety ${ }^{*}$ priming and stress* ${ }^{*}$ priming were non-significant. Sahiwal-2002 showed a significant increase in total chlorophyll content with priming under control conditions (Figure 6a). Sadaf showed a significant 
increase in total chlorophyll content with priming under saline conditions. Sadaf indicated a non-significant effect of priming under control conditions. Sahiwal-2002 indicated a non-significant effect of priming under saline conditions.

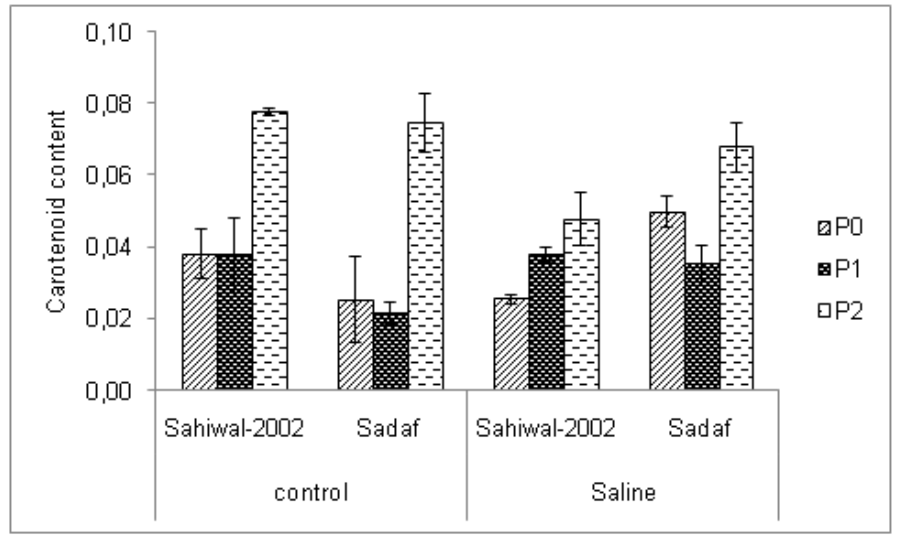

(A)

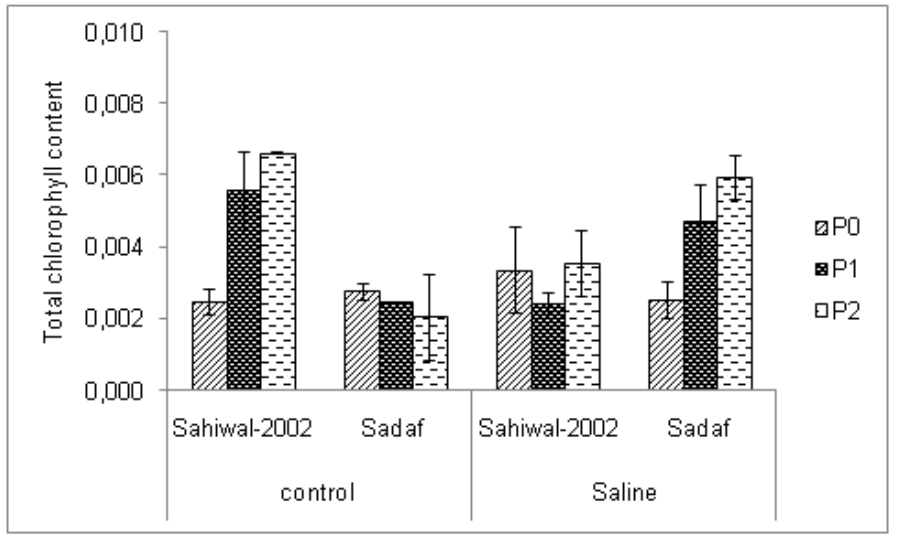

(B)

Figure 6. Priming effect changes on (a) carotenoids and (b) total chlorophyll contents of different tolerant varieties under saline and control conditions.

Both varieties showed a similar level of Chl-a in both conditions when nonprime. The priming increased this attribute in stress only in Sadaf and in Sahiwal under controlled conditions. Like Chl-a both varieties showed a similar level of Chl-b in both conditions when nonprime. The priming increased this attribute in stress only in Sadaf and in Sahiwal under controlled conditions. Varietal differences and the effect of stress were negligible for these carotenoids. However, priming showed a great rise in both varieties. Sahiwal-2002 showed a significant increase in total chlorophyll content with priming under control conditions. Sadaf showed a significant increase in total chlorophyll content with priming under saline conditions. Sadaf indicated a nonsignificant effect of priming under control conditions. Sahiwal-2002 indicated a non-significant effect of priming under saline conditions. The seed priming help to cope with the oxidative damage under salinity stress.

Chlorophyll content in plant leaves decreases due to $\mathrm{NaCl}$ [26]. Due to diminished chlorophyll biosynthesis, nutrient deficiency, and enhanced chlorophyllase activity, the depressive effects of salinity on leaf chlorophyll contents might be recognized [27]. Reduction in photosynthesis in the salinized plants depended on the effects of leaf water and osmotic potential, stomatal conductance, transpiration rate, proteins relative leaf water content, and biochemical constituents such as photosynthetic pigments, soluble carbohydrates, and reduction of available $\mathrm{CO} 2$ by stomatal closure. Which resulted in low concentrations of assimilates in the leaves [9]. Reduced grain dry matter was appeared due to these low concentrations and poor translocation of assimilates [28]. The net photosynthesis rates were greatly decreased by high salinity. In the recent study, under high salt stress, the chlorophyll contents extensively decreased, such as pea [29]. In wheat, photosynthesis is well-linked within different salt concentrations, as growth stage, stomatal conductance, genotypes, time of the day, and duration of salt exposure [30]. The photosynthesis required the standard conditions, because shading of lower leaves, rates of decline with leaf aging, and time of the day when measurements were made could be different among plant material, so it cannot be determined by the single experiment. Under salt stress to observe the balance of photosynthates within plants, net photosynthesis is affected by respiration [31]. Except as a secondary effect in already heavily salt-affected leaves photosynthesis is not drastically reduced by salinity leaf thickening and adaptation of leaves to saline conditions appears for example osmotic adjustment in wheat [32].

\section{Carotenoids content}

The statistical data showed that differences between the variety and stress were significant for carotenoids (Table 2). The difference between priming was non-significant. The interaction between variety*stress* priming was non-significant. Varietal difference and the effect of stress as negligible for this attribute. However, the priming showed a great rise in both varieties (Figure 6b).

\section{CONCLUSION}

This study was focusing on determining the response of two differentially salt-tolerant maize varieties at 
the seedling stage. Under saline conditions through different strategies, significant achievements have been made in improving crop productivity. Phenylalanine has successfully increased salinity tolerance in maize at the seedling stage.

Funding: This research received no external funding.

Conflicts of Interest: The authors declare no conflict of interest.

\section{REFERENCES}

1. Sabagh AE, Hossain A, Barutçular C, Islam MS, Ratnasekera D, Kumar N, Meena RS, Gharib HS, Saneoka H, da Silva JA. Drought and salinity stress management for higher and sustainable canola ('Brassica napus' L.) production: A critical review. Aus J Crop Sci. 2019 Jan; 13(1):88.

2. Marino G, Zaccaria D, Lagos LO, Souto C, Kent ER, Grattan SR, Shapiro K, Sanden BL, Snyder RL. Effects of salinity and sodicity on the seasonal dynamics of actual evapotranspiration and surface energy balance components in mature micro-irrigated pistachio orchards. Irri Sci. 2020 Oct; 15:1-21.

3. Hafeez MB, Raza A, Zahra N, Shaukat K, Akram MZ, Iqbal S, Basra SM. Gene regulation in halophytes in conferring salt tolerance. InHandbook of Bioremediation (pp. 341-370). Academic Press.

4. Zhu JK. Salt and drought stress signal transduction in plants. Ann Rev Plant Biol. 2002 Jun; 53(1):247-73.

5. Ismail AM, Horie T. Genomics, physiology, and molecular breeding approaches for improving salt tolerance. Annual Review of Plant Biology. 2017 Apr; 68:405-34.

6. Shoji T, Suzuki K, Abe T, Kaneko Y, Shi H, Zhu JK, Rus A, Hasegawa PM, Hashimoto T. Salt stress affects cortical microtubule organization and helical growth in Arabidopsis. Plant Cell Physiol. 2006 Aug; 47(8):1158-68.

7. Acosta-Motos JR, Ortuño MF, Bernal-Vicente A, Diaz-Vivancos P, Sanchez-Blanco MJ, Hernandez JA. Plant responses to salt stress: adaptive mechanisms. Agronomy 2017 Mar; 7(1):18.

8. Zahra N, Mahmood S, Raza ZA. Salinity stress on various physiological and biochemical attributes of two distinct maize (Zea mays L.) genotypes. J Plant Nutr. 2018 Jul; 41(11):1368-80.

9. Iqbal S, Basra SM, Afzal I, Wahid A, Saddiq MS, Hafeez MB, Jacobsen SE. Yield potential and salt tolerance of quinoa on salt-degraded soils of Pakistan. J Agron Crop Sci. 2019 Feb; 205(1):13-21.

10. Conrath U, Beckers GJ, Flors V, García-Agustín P, Jakab G, Mauch F, Newman MA, Pieterse CM, Poinssot B, Pozo MJ, Pugin A. Priming: getting ready for battle. Mol Plant-microbe Interact. 2006 Oct; 19(10):1062-71.

11. Saddiq MS, Iqbal S, Afzal I, Ibrahim AM, Bakhtavar MA, Hafeez MB, Jahanzaib, Maqbool MM. Mitigation of salinity stress in wheat (Triticum aestivum L.) seedlings through physiological seed enhancements. J Plant Nutr. 2019 Jun; 42(10):1192-204.

12. Farooq M, Rehman A, Al-Alawi AK, Al-Busaidi WM, Lee DJ. Integrated use of seed priming and biochar improves salt tolerance in cowpea. Sci Hortic. 2020 Oct; 272:109507.

13. Askari A, Ardakani MR, Paknejad F, Hosseini Y. Effects of mycorrhizal symbiosis and seed priming on yield and water use efficiency of sesame under drought stress condition. Sci Hortic. 2019 Nov; 257:108749.

14. Arif M, Jan MT, Marwat KB, Khan MA. Seed priming improves emergence and yield of soybean. Pak J Bot. 2008 Jun; 40(3):1169-77.

15. Zahra N, Wahid A, Shaukat K, Rasheed T. Role of seed priming and foliar spray of calcium in improving flag leaf growth, grain filling and yield characteristics in wheat (Triticum aestivum) - a field appraisal. Intl J Agric Biol. 2020 Oct; 24:1591-1600

16. Leubner-Metzger G, Nakabayashi K. Coleorhiza-enforced seed dormancy: a novel mechanism to control germination in grasses. New Phytol. 2020: DOI: https://doi.org/10.1111/nph.16948

17. Arnon DI. Copper enzymes in isolated chloroplasts. Polyphenoloxidase in Beta vulgaris. Plant Physiol. 1949 Jan; 24(1):1.

18. Davis BH. Biosynthesis of carotenoids. In: Chemistry and Biochemistry of Plant Pigments. Ed. T. W. Goodwin, $2^{\text {nd }}$ Edn. Academic Press London, 1976, p 262.

19. Shahid MA, Sarkhosh A, Khan N, Balal RM, Ali S, Rossi L, Gómez C, Mattson N, Nasim W, Garcia-Sanchez F. Insights into the Physiological and Biochemical Impacts of Salt Stress on Plant Growth and Development. Agronomy. $2020 \mathrm{Jul} ; 10(7): 938$.

20. Koyro HW. Effect of salinity on growth, photosynthesis, water relations and solute composition of the potential cash crop halophyte Plantago coronopus (L.). Environ Exp Bot. 2006 Jun; 56(2):136-46.

21. Cheng R, Zhu, H, Cheng, X, Shutes, B, Yan, B. Saline and Alkaline tolerance of wetland plants-what are the most representative evaluation indicators?. Sustainability 2020 March 3;12(5), p.1913.

22. Iqbal S, Hussain S, Qayyaum MA, Ashraf M. The Response of Maize Physiology under Salinity Stress and Its Coping Strategies. InPlant Stress Physiology 2020 Jun 1. IntechOpen. 
23. Yan H, Shah SS, Zhao W, Liu F. Variations in water relations, stomatal characteristics, and plant growth between quinoa and pea under salt-stress conditions. Pak J Bot. 2020 Feb 1; 52(1):1-7.

24. Siddiqui H, Hayat S, Bajguz A. Regulation of photosynthesis by brassinosteroids in plants. Acta Physiol Plant 2018 Mar; 40(3):59.

25. Chandrasekaran M, Chanratana M, Kim K, Seshadri S, Sa T. Impact of arbuscular mycorrhizal fungi on photosynthesis, water status, and gas exchange of plants under salt stress-a meta-analysis. Front Plant Sci. 2019 Apr; 10:457.

26. Shin YK, Bhandari SR, Cho MC, Lee JG. Evaluation of chlorophyll fluorescence parameters and proline content in tomato seedlings grown under different salt stress conditions. Hortic Environ Biotechnol. 2020 Apr; 61:433-43

27. Altuntaş C, Demiralay M, Muslu AS, Terzi R. Proline-stimulated signaling primarily targets the chlorophyll degradation pathway and photosynthesis associated processes to cope with short-term water deficit in maize. Photosyn Res. 2020 Feb; 28:1-4.

28. Yadav T, Kumar A, Yadav RK, Yadav G, Kumar R, Kushwaha M. Salicylic acid and thiourea mitigate the salinity and drought stress on physiological traits governing yield in pearl millet-wheat. Saudi J Biol Sci. 2020 Aug 1;27(8):2010-7.

29. Kafi $M$. The effects of salinity and light on photosynthesis, respiration and chlorophyll fluorescence in salt-tolerant and salt-sensitive wheat (Triticum aestivum L.) cultivars. Agri Sci Technol. 2009; 11:535-47.

30. Maha A, Sanaa I, Mabrook YM, Amira Y, Gouda MA. Evaluation of some Egyptian bread wheat (Triticum aestivum) cultivars under salinity stress. Alex Sci Exch J 2017; 38(260):2.

31. Jiang C, Zu C, Lu D, Zheng Q, Shen J, Wang H, Li D. Effect of exogenous selenium supply on photosynthesis, $\mathrm{Na}+$ accumulation and antioxidative capacity of maize (Zea mays L.) under salinity stress. Sci Rep. 2017 Feb; 7:42039.

32. Ali Y, Aslam Z, Sarwar G, Hussain F. Genotypic and environmental interaction in advanced lines of wheat under salt-affected soils environment of Punjab. Int J Environ Sci Technol. 2005 Sep; 2(3):223-8.

(C) 5 (1) 2020 by the authors. Submitted for possible open access publication under the terms and
conditions of the Creative Commons Attribution (CC BY NC) license
(https://creativecommons.org/licenses/by-nc/4.0/). 